DOI: 10.18468/letras.2017v7n2.p91-116

\title{
LICENCIAMENTO DE DUPLOS SUJEITOS EM VARIEDADES DO \\ PORTUGUÊS: PESSOA, DEFINITUDE E ESTRUTURA DE TRAÇOS
}

\author{
Claudia Roberta Tavares Silva ${ }^{1}$ \\ Danniel da Silva Carvalho \\ Fernanda Maciel Ziober $^{3}$
}

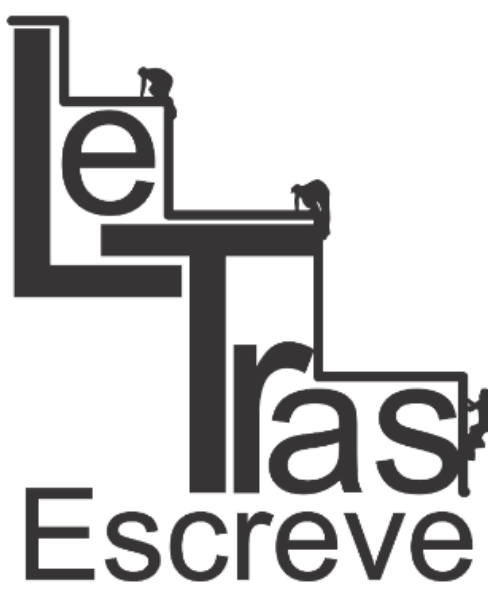

(ISSN 2238-8060)

Resumo: Este artigo, inserido no âmbito da sintaxe comparativa, estabelece uma comparação entre variedades do português, a saber: o português europeu ( $P E)$, o português brasileiro (PB), o português de Moçambique (PM), de Angola (PA), de Guiné-Bissau (PGB), de São Tomé e Príncipe (PST) e de Cabo Verde (PCV), centrando a atenção no licenciamento de duplos sujeitos (DSs). Para tanto, o corpus da pesquisa constitui-se de contextos declarativos finitos extraídos de entrevistas informais. Estudos têm revelado que em PB predominam DSs com o traço de $3^{a}$ pessoa, ao contrário de outras línguas, como é o caso do crioulo caboverdiano e do Santome cuja predominância é da 1a pessoa do singular. Visando estabelecer o estudo interlinguístico proposto, abordamos os traços de pessoa e de definitude e propomos uma reinterpretação de uma geometria de traços que culmina em uma hierarquia interna aos pronomes relevante para sua realização morfológica e para a sintaxe. Com base nesse modelo, propomos a inclusão do traço pessoa (a saber, $[\pi]$ ) considerado empiricamente necessário, o que implica considerarmos de que esse traço é inerente ao pronome e não ao verbo. Retomando também a proposta de composição de traços e observando os traços relevantes para a valoração de pessoa, levantamos como hipótese que entre o PB e as demais variedades do português, diferentes subespecificações de traços de pessoa estão envolvidas nas estruturas de DSs entendidas como estruturas tópicas que possuem um pronome resumptivo na posição do sujeito movido.

Palavras-chave: Traço. Pessoa. Composicionalidade. Sujeito.

Abstract: This paper establishes a comparison, on the basis of comparative syntax, among a number of varieties of Portuguese, namely: European Portuguese (EP), Brazilian Portuguese (BP), Mozambique (MP), Angola (AP), Guinea-Bissau (GBP), São Tomé and Príncipe (STP) and Cape Verde (CVP) Portuguese, focusing attention on person feature in context of double sub-

\footnotetext{
${ }^{1}$ Doutora em Linguística, professora associada da Universidade Federal Rural de Pernambuco (UFRPE) e professora junto ao Programa de Pós-Graduação em Letras da Universidade Federal de Pernambuco (UFPE). E-mail: claudiarobertats@gmail.com

${ }^{2}$ Doutor em Linguística e professor associado da Universidade Federal da Bahia (UFBA). E-mail: dannielcarvalho@ufba.br

${ }^{3}$ Doutoranda em Linguística pela Vrije Universiteit Amsterdam (VU) e bolsista da CAPES (Processo no: 1834/15-0). E-mail: fernandaziober@gmail.com
}

https://periodicos.unifap.br/index.php/letras

Macapá, v. 7, n. 2, 2을 semestre, 2017. 


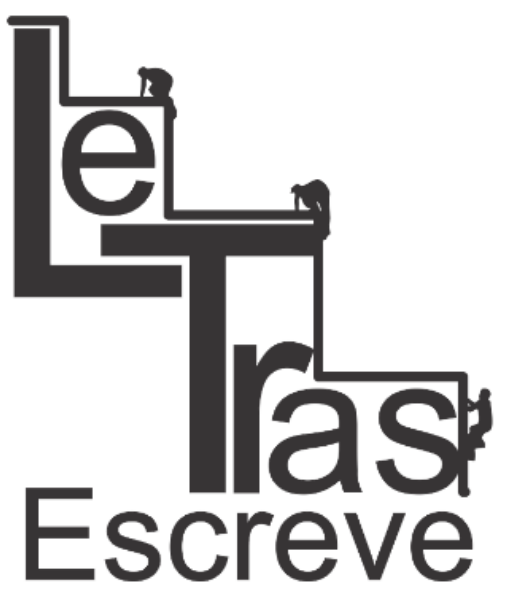

(ISSN 2238-8060) jects (DSs). To do so, we costituted a corpus composed of finite declarative sentence extracted from informal interviews. Studies have shown that DSs with third person feature prevail in BP, unlike other languages, as the case of Cape Verdean Creole and Santome, in which first person singular prevails. In order to develop a cross-linguistic study, we approach person and definiteness features and proposed a reinterpretation of a feature geometry which culminates in a pronominal internal hierarchy which is relevant for its morphological realization and syntax. Based on this approach, we propose the inclusion of the person feature (namely, $[\pi]$ ) considered empirically necessary, which implies that this feature is inherent to the pronoun and not the verb. Also resuming the proposal of a feature composition and observing the relevant fetures for the value of person, we raise as hypothesis that between PB and the other varieties of Portuguese, different subspecifications of the person feature are involved in the structures of DSs understood as topic structures which have a resumptive pronoun in the position of the moved subject.

Keywords: Feature. Person. Compositionality. Subject.

\section{Introdução}

A formação do português revela uma dinâmica sociolinguística embasada no contato com línguas de diferentes povos, sendo impossível sustentar um discurso pautado no monolinguismo quer seja na dimensão sincrônica, quer seja diacrônica. Sobre o contato multilinguístico, destaca Mattos e Silva (1988, p. 16): “[c]ontrariamente ao que ocorre no português europeu, em todas as outras áreas lusófonas, o português se encontra em situações complexas e diversas de multilinguismo e aí está incluído o Brasil". Portanto, longe de ser uma abordagem generalizante do português devido à complexidade linguística nos países lusófonos do continente africano (cuja independância de Portugal ocorre na segunda metade do século XX) e no Brasil (que se torna independente de Portugal na primeira medade do século XIX), além da constituição político-econômico-cultural que é peculiar a cada país, adotaremos aqui a terminologia variedades do português, centrando nossa atenção nas seguintes variedades, a saber: o português europeu (PE), o português brasileiro (PB), o portu-

https://periodicos.unifap.br/index.php/letras

Macapá, v. 7, n. 2, 2o semestre, 2017. 


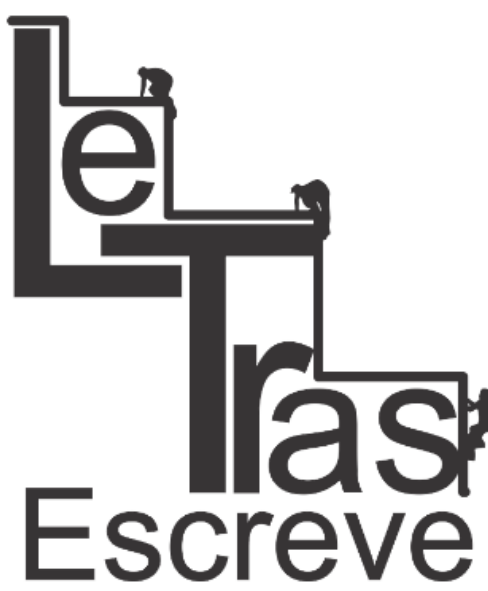

(ISSN 2238-8060)

guês de Angola (PA), o português de Moçambique (PM), o português de Guiné-Bissau (PGB), o português de São Tomé e Príncipe (PST) e o português de Cabo Verde (PCV).

Vale referirmos que, embora o Brasil e os países lusófonos do continente africano estejam inseridos em um contexto intenso de multilinguismo, estudos linguísticos revelam que as variedades africanas do português apresentam usos mais próximos da norma padrão da variedade europeia do português (BACELAR DO NASCIMENTO et al., 2008; MOTA, 2015). Apesar dessa proximidade, Bacelar do Nascimento et al. (2008, p. 380-383) verificam variação linguística no âmbito da sintaxe e da morfossintaxe, por exemplo, em dados extraídos do Corpus África ${ }^{4}$, do Centro de Linguística da Universidade de Lisboa: no primeiro caso, dá-se destaque à colocação pronominal (em contextos de ênclise, é produzida a próclise (cf. (1a) a (1c)) e vice-versa (cf. (1d) a (1f)) e, no segundo, ao uso dos pronomes tu e você (a alternância do pronome você com pronomes de segunda pessoa (cf. (2a) a (2c)) e do pronome tu com a forma verbal de terceira pessoa do verbo ver, por exemplo (cf. $(2 d))$ :

a. "portanto se arquitectou a ideia de admitir mulheres" CV(O)

b. "se faz o tratamento da lepra ali" G(O)

c. "depois se prepara ir na escola." $A(O)$

d. "quando o doutor Pinto retira-se." $A(O)$

e. "eram as únicas pessoas que serviam-nos como mães e pais" $M(O)$

f. “há quem diga que corta-se a palmeira não é? ST(O)

\footnotetext{
${ }^{4}$ Este corpus é constituído de 5 subcorpora orais (O) e escritos ((J(ornais), L(ivros literários)) por contemplar as cinco variedades africanas do português, a saber: Angola (A), Moçambique (M), Cabo Verde (CV), Guiné-Bissau (G) e São Tomé e Príncipe (ST).
}

https://periodicos.unifap.br/index.php/letras

Macapá, v. 7, n. 2, 2o semestre, 2017. 

a. "você lava um carro te dão os quinhentos mil" $\mathrm{A}(\mathrm{O})$
b. "aí você cultiva vai na tuas lavra" A(O)
c. "você quer receber teu dinheiro" ST(O)
d. "tu passas e vê o lixo." G(O)

Comparando o PM e o PA com o PB, Petter (2009) observa que este apresenta mais estabilidade, ao contrário daqueles que ainda possuem um contato recente com PE e recebem influência das línguas bantu (L1). Além disso, a maior ou menor utilização de outra língua (distinta do português) favorece, respectivamente, uma maior ou menor proximidade com o PE. Segundo Petter (2009, p. 203), “[n]a África, embora seja língua oficial, que é utilizada na administração e no ensino, o português é adquirido, prioritariamente, como segunda língua, que tem por modelo a variedade européia 5." (PETTER, 2009, p. 203). Para entendermos um pouco essa complexidade, confira a Tabela 1 , em que há um quadro-resumo com as línguas mais faladas que convivem com o português.

Tabela 1 - Língua(s) mais usada(s) e língua oficial em cinco países africanos lusófonos

\begin{tabular}{|c|c|c|}
\hline PAÍS & LÍNGUA MAIS FALADA & LÍNGUA OFICIAL \\
\hline Angola & $\begin{array}{l}\text { Línguas do grupo bantu (família } \\
\text { benue-congo ocidental): a) um- } \\
\text { bundo (língua materna falada por } \\
\text { cerca de um terço dos angolanos - } \\
22,96 \%) \text {; b) kimbundo (língua fala- } \\
\text { da pela quarta parte da população } \\
-7,82 \%) \text {; c) kikongo ( } 8,24 \%) \text {; d) } \\
\text { côkwe (6.54\%), e) ganguela } \\
\begin{array}{lll}(3,11 \%) \text { e f) cuanhama }(2,26 \%) . & \end{array}\end{array}$ & $\begin{array}{l}\text { Português } \\
\text { primeira ou se- } \\
\text { gunda língua, fa- } \\
\text { lada por } 71 \% \text { dos } \\
\text { angolanos } 7\end{array}$ \\
\hline
\end{tabular}

\footnotetext{
${ }^{5}$ Conservou-se a grafia usada no texto-fonte.

${ }^{6}$ https://pt.wikipedia.org/wiki/Angola\#L.C3.ADnguas

${ }^{7}$ https://pt.wikipedia.org/wiki/Angola\#cite_note-57. Informação contida no Observatório da Língua Portuguesa. Consultado em 30 de março de 2016
}

https://periodicos.unifap.br/index.php/letras

Macapá, v. 7, n. 2, 2o semestre, 2017. 


\begin{tabular}{|c|c|c|}
\hline Moçambique & $\begin{array}{l}\text { Línguas do grupo bantu (família } \\
\text { benue-congo): a) macua (emakhu- } \\
\text { wa) (língua materna falada por } \\
26,3 \% \text { ); b) changana (língua ma- } \\
\text { terna falada por } 11,4 \% \text { ) e c) elom- } \\
\text { we (língua materna falada por } \\
7,9 \%)^{8} \text {. }\end{array}$ & $\begin{array}{l}\text { Português } \\
\text { cerca de } 50 \% \text { fa- } \\
\text { lam português } \\
(10,7 \% \text { dos falan- } \\
\text { tes consideram- } \\
\text { no língua mater- } \\
\text { na e } 39,7 \% \text {, co- } \\
\text { mo segunda lín- } \\
\text { gua (GONÇAL- } \\
\text { VES, 2015) }\end{array}$ \\
\hline Cabo Verde & $\begin{array}{l}\text { Língua materna: crioulo caboverdi- } \\
\text { ano (quase todos os caboverdianos } \\
\text { falam-na ( } 926.078 \text { falantes) }\end{array}$ & $\begin{array}{l}\text { Português } \\
87 \% \text { falam por- } \\
\text { tuguês }^{10}\end{array}$ \\
\hline $\begin{array}{l}\text { São Tomé e } \\
\text { Príncipe }\end{array}$ & $\begin{array}{l}\text { Línguas crioulas: a) santomé/ forro } \\
\text { (língua de São Tomé): } 72,4 \% \text { (maio- } \\
\text { res de cinco anos) (HAGEMEIJER, } \\
2009)^{11} ; \text { b) angolar (língua dos } \\
\text { Angolares): } 5,3 \% \text { da população } \\
\text { (LORENZINO, 1996) e c) lung'ie } \\
\text { (língua do Príncipe): } 2,4 \% \text { (mais de } \\
\text { cinco anos de idade) (HAGEMEIJER, } \\
2009)^{12} \text {. }\end{array}$ & $\begin{array}{l}\text { Português } \\
\text { 98,4\% falam } \\
\text { português }^{13}\end{array}$ \\
\hline Guiné-Bissau & $\begin{array}{l}\text { crioulo guineense (língua materna } \\
\text { falada por cerca de } 80 \% \text { da popula- } \\
\text { ção) (OLIVEIRA; BAIO; INJAI, 2013) }\end{array}$ & $\begin{array}{l}\text { Português } \\
\text { Cerca de } 13 \% \text { da } \\
\text { população usam- } \\
\text { na como língua } \\
\text { segunda ou ter- } \\
\text { ceira } \\
\text { (COUTO; EMBA- } \\
\text { LÓ, 2010) }\end{array}$ \\
\hline
\end{tabular}

(ISSN 2238-8060)

Os dados apresentados no quadro revelam um pouco a complexidade linguística do continente africano devido ao contexto de multilinguismo intenso. No que se refere ao português, constitui-se língua oficial em todos os países, embora não seja a mais falada em

\footnotetext{
${ }^{8}$ Instituto Nacional de Estatística de Moçambique Línguas mais faladas em Moçambique, de acordo com o censo de 1997

${ }^{9}$ https://pt.wikipedia.org/wiki/Crioulo_cabo-verdiano

${ }^{10}$ Informação extraída do Observatório da Língua Portuguesa: https://observalinguaportu guesa.org/category/dados-estatisticos/

${ }^{11}$ Censo de 2001.

${ }^{12}$ Censo de 2001.

13 https://pt.wikipedia.org/wiki/S\%C3\%A3o_Tom\%C3\%A9_e_Pr\%C3\%ADncipe\#cite_notecia-1«Sao Tome and Principe in CIA World Factbook». CIA. Consultado em 16 de dezembro de 2016.
}

https://periodicos.unifap.br/index.php/letras

Macapá, v. 7, n. 2, 2o semestre, 2017. 
comparação às línguas do grupo bantu, faladas em Moçambique e em Angola e as línguas crioulas faladas em Cabo Verde e Guiné-Bissau; em particular, nesse último país, o português é muito pouco falado em relação ao crioulo guineense, diferentemente do que ocorre em São Tomé e Príncipe (GONÇALVES, 2012) que é o "único país da África de língua portuguesa onde a maioria da população tem actualmente o Português como primeira língua, havendo assim condição para a emergência de uma nova variedade." (HAGEMEIJER, 2009, p. 19-20).

A partir das considerações feitas, deteremos nossa atenção nas variedades europeia, africana e brasileira do português no que se refere ao comportamento dos sujeitos em construções em que são redobrados por um pronome resumptivo (os chamados "duplos sujeitos" (doravante, DSs), caracterizando-se como estruturas tópicas que possuem um resumptivo na posição do sujeito movido, conforme evidenciam dados extraídos dos corpora desta pesquisa:

a. "só que eu depois eu questiono-me se o nosso está em sétimo lugar como é que estarão os outros - porque é que a violência de dia para dia está a piorar bastante"(PE)

b. “[...] meu irmão... ele num é home pa juntá um casal... [...] (PB)

c. "e nós nós propusemos, montar vinte e três equipas móveis." (PA)

d. "...quer dizer elas elas quando começam a namorar com um homem..." (PM)

e. meu avô, ele também me dá apoio. (PGB)

f. até dizem até dizem que a casca é, é veneno. mas, eu eu creio que a forma de contaminação, porque não sei. (PSTP)

g. Ele, ele é um pouco ciclotímico[...] (PCV) 
Desde a década de 80, com o trabalho pioneiro de Pontes (1986), os DSs em PB vêm merecendo atenção e sua grande produtividade tem sido explicada pelo enfraquecimento da morfologia de flexão verbal e consequente reorganização do paradigma pronominal na gramática dessa língua, o que tem ocasionado o grande aumento de sujeitos plenos na posição pré-verbal, resultante, segundo Duarte $(1995,2000)$ de um processo de mudança na marcação do valor do Parâmetro do Sujeito Nulo (PSN).

Ao contrário do $\mathrm{PE}$, uma língua de sujeito nulo consistente (BARBOSA, 1996), DSs são muito produtivos na gramática do PB, uma língua de sujeito nulo parcial (HOLMBERG; NAYUDU; SHEEHAN, 2009). Barbosa (2009) ainda observa, citando outros autores que trataram do italiano e do espanhol, que construções com DSs são muito raras em línguas pro-drop consistentes. Além dessa assimetria entre o PB e o PE no que se refere à produtividade de DSs, naquela é predominante o traço de terceira pessoa desses sujeitos, diferentemente do que se observa no crioulo falado em Cabo Verde e São Tomé (SILVA, 2013; SILVA; ZIOBER, 2014).

Tendo em vista a escassez de estudos no âmbito da sintaxe das (ISSN 2238-8060) variedades africanas do português, este estudo, situado no campo da sintaxe comparativa, visa a uma comparação do comportamento dos DSs dessas variedades com o PB e o PE, centrando a atenção nos traços de pessoa e definitude desses sujeitos, levantando como hipótese de que os padrões encontrados para os DSs nas variedades africanas vão na direção dos encontrados na variedade europeia pelo fato de entre o PB e essas variedades haver diferentes subespecificações de traços de pessoa envolvidas no contexto de DSs, tomando por base a proposta de composição de traços para o PB (CARVALHO, 2008) e os traços relevantes para a valoração de pessoa (CARVALHO; BRITO, 
2014; CARVALHO, 2015). Dessa maneira, será possível contribuirmos com o tratamento dado à categoria pessoa no âmbito da teoria de valoração e composicionalidade de traços (HARLEY; RITTER, 2002), bem como com os estudos gerativistas sobre a sintaxe comparada entre variedades do português.

Vale referirmos ainda que os dados submetidos à análise foram coletados de diferentes fontes, a saber:

a) no PB, de estudos realizados sobre essa variedade e da pesquisa de Silva (2013), esta última com base em vinte e oito entrevistas realizadas em duas comunidades quilombolas da região nordeste, a saber: a) a comunidade Muquém, localizada na Zona da Mata do Estado de Alagoas, onde foram realizadas catorze entrevistas (MOURA, 2009) e b) as comunidades Pêga, Arrojado e Engenho Novo, localizadas no extremo oeste da zona rural do município Portalegre no Estado do Rio Grande do Norte, onde também foram realizadas catorze entrevistas (SOUZA et al., 2011);

b) no $\mathrm{PE}$, de estudos já realizados sobre essa variedade e do corpus disponível no site http://www.concordancia.letras.ufrj.br/ que foi resultado da pesquisa conjunta sobre o fenômeno da concordância entre a Universidade Federal do Rio de Janeiro (UFRJ) e o Centro de Linguística da Universidade de Lisboa (CLUL). Para esta pesquisa, utilizou-se o total de vinte e duas entrevistas informais coletadas em Oeiras, distrito de Lisboa, sendo o corpus constituído de trinta e três ocorrências de DSs;

c) no PA, de pesquisas sobre essa variedade e do corpus disponível no site: $\quad$ http://www.clul.ul.pt/pt/recursos/184-vapor-african-varie ties-of-portuguese que se encontra relacionado ao projeto Varie- 


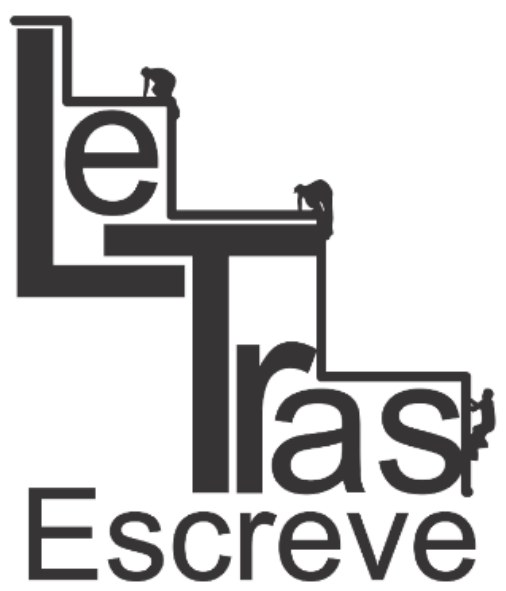

(ISSN 2238-8060)

dades Africanas do Português (VAPOR) ${ }^{14}$, do CLUL. Trata-se de dezesseis entrevistas informais gravadas em 2009, contendo aproximadamente duas horas de gravação e um total de 27.363 palavras e sendo o corpus constituído de apenas quatro ocorrências de DSs;

d) no PM, de pesquisas sobre essa variedade e do Corpus Português Oral de Moçambique 1986-87, elaborado por Perpétua Gonçalves, sendo composto de quarenta e oito transcrições de entrevistas informais com alunos da Faculdade de Educação da Universidade Eduardo Mondlane (UEM), participantes do Programa de Formação de Professores de Língua Portuguesa, tendo 140.198 palavras no tota $\left.\right|^{15}$. Esse corpus encontra-se disponível no Corpus Query Processor (CPQweb) do CLUL, a saber: http://alfclul.clul.ul.pt/ CQPweb/moz/. Para a composição do corpus deste estudo, foram selecionadas dezessete ocorrências de DSs;

e) no PGB, de pesquisas sobre essa variedade e do corpus extraído do site: http://www.clul.ul.pt/pt/recursos/184-vapor-african-varietiesof-portuguese do projeto Variedades Africanas do Português (VAPOR), do CLUL. Trata-se de dezoito entrevistas informais gravadas em 1995, contendo um total de 25.016 palavras. Para o corpus desta pesquisa, foram selecionadas catorze ocorrências de DSs;

f) no PST, de pesquisas sobre essa variedade e do corpus extraído do

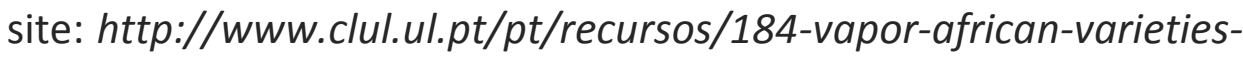
of-portuguese do projeto Variedades Africanas do Português (VAPOR), do CLUL. Trata-se de treze entrevistas informais gravadas em 2008, 2011 e 2012, contendo aproximadamente setenta e seis ho-

\footnotetext{
${ }^{14}$ Agradecemos ao professor Tjerk Hagemeijer, um dos coordenadores desse projeto, por permitir o acesso aos dados sem os quais não seria possível a realização deste estudo.

${ }^{15}$ Embora apontado por um parecerista anônimo que a quantidade de palavras do corpus do PM seja bem superior ao das demais variedades do português, causando uma assimetria entre os corpora, verificamos neste estudo que tal diferença não implicou maior produção de DSs nessa variedade.
}

https://periodicos.unifap.br/index.php/letras

Macapá, v. 7, n. 2, 2ㅇ semestre, 2017. 
ras de gravação e um total de 25.287 palavras. O corpus deste estudo é constituído de apenas três ocorrências de DSs;

g) no PCV, de pesquisas sobre essa variedade e do corpus extraído do site: $h t t p: / / w w w . c l u l . u l . p t / p t / r e c u r s o s / 184-v a p o r-a f r i c a n-v a r i e t i e s-$ of-portuguese. Trata-se de vinte entrevistas informais gravadas em 2008 e 2009, contendo aproximadamente nove horas de gravação e um total de 25.413 palavras e sendo selecionadas dez ocorrências de DSs para a composição do corpus desta pesquisa.

Para a realização do estudo, este artigo encontra-se assim estruturado: na seção 2, serão apresentados os padrões de comportamento dos DSs nas variedades do português em análise, tomando por base o traço de pessoa do pronome resumptivo e de definitude desses sujeitos; na seção 3, será realizada a análise dos dados obtidos, centrando a atenção no licenciamento dos DSs e, na seção 4, apresentaremos as considerações finais.

2 Padrões de comportamento dos duplos sujeitos nas variedades europeia, brasileira e africana do português

Araújo (2009), ao estudar construções de tópicos em quatro comunidades rurais afro-brasileiras isoladas do interior do Estado da Bahia - Helvécia (07), Cinzento (07), Rio de Contas (06) e Sapé (06) pontua que, embora DSs sejam muito produtivos no português coloquial urbano (DUARTE, 2000; SALLES, 2004), são pouco produzidos na língua falada dessas comunidades. Segundo ela, esses sujeitos caracterizam-se como sintagmas nominais definidos, identificáveis, ativos e referenciais, realizados por um nome ou pronome.

Tomando por base o estudo de Araújo (2009) e levando em

https://periodicos.unifap.br/index.php/letras

Macapá, v. 7, n. 2, 2o semestre, 2017. 


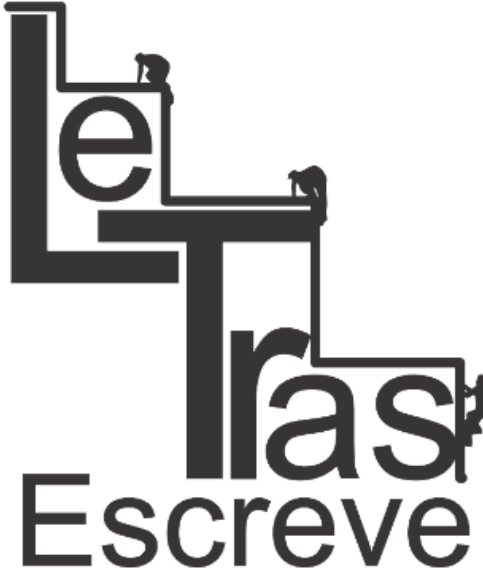

(ISSN 2238-8060)

conta as variáveis definitude do DP sujeito e pessoa do pronome resumptivo, vale retomarmos aqui os resultados obtidos por Silva (2013) ao analisar o comportamento de DSs na língua falada em duas comunidades quilombolas do nordeste brasileiro, a saber: a) a comunidade de Muquém, localizada na Zona da Mata do Estado de Alagoas, mas não tão afastada do meio urbano e b) as comunidades Pêga, Arrojado e Engenho Novo, localizadas no extremo oeste da zona rural do município Portalegre no Estado do Rio Grande do Norte e bastante afastadas do meio urbano. Levar em conta o grau de afastamento dessas comunidades em relação ao meio urbano foi fundamental para essa autora testar a seguinte hipótese: quanto mais próxima for a comunidade desse meio, maior o contato com o português coloquial urbano e, portanto, maior compartilhamento de propriedades dos DSs produzidos nessa comunidade e no meio urbano.

Os resultados retomados de Silva (2013) e apresentados na Tabela 2 revelam que as duas comunidades possuem um comportamento um pouco distinto: em Muquém, há uma predominância, quase que massiva, de DSs definidos com o traço de terceira pessoa; já, nas demais comunidades, todos os DSs são definidos, havendo também o predomínio da terceira pessoa:

Tabela 2 - Ocorrência e percentual de Duplos Sujeitos em duas comunidades quilombolas brasileiras.

\begin{tabular}{cccrcr}
\hline UF da comunidade & \multicolumn{2}{c}{ ALAGOAS } & RIO GRANDE DO NORTE \\
\hline \multirow{2}{*}{ Definitude } & {$[$ [+definido] } & 26 & $92.8 \%$ & 30 & $100 \%$ \\
\cline { 2 - 7 } & {$[$-definido] } & 2 & $7.1 \%$ & -- & $0 \%$ \\
\hline & 1.p.s. & 1 & $3.5 \%$ & 3 & $10 \%$ \\
\cline { 2 - 6 } & 2.p.s. & -- & $0 \%$ & 2 & $6.6 \%$ \\
\cline { 2 - 6 } $\begin{array}{c}\text { Pessoa do } \\
\text { pronome re- } \\
\text { sumptivo }\end{array}$ & 3.p.s. & 20 & $71.4 \%$ & 20 & $66.6 \%$ \\
\cline { 2 - 6 } & 2.p.p. & 1 & $3.5 \%$ & 4 & $13.3 \%$ \\
\cline { 2 - 6 } & 3.p.p. & 6 & $21.4 \%$ & 1 & $0 \%$ \\
\hline
\end{tabular}

Fonte: Silva (2013, p. 194).

https://periodicos.unifap.br/index.php/letras

Macapá, v. 7, n. 2, 2으 semestre, 2017. 
Contrariamente aos dados apresentados na Tabela 2, predominam, nas demais variedades do português, DSs com o traço de primeira pessoa (ver Figura 1, a seguir). Sobre essa assimetria, discutiremos na próxima seção ao abordarmos a valoração e a composicionalidade dos traços em estruturas de DSs:

Figura 1 - Frequência relativa de DS em variedades do português, tomando por base o traço de pessoa ${ }^{16}$

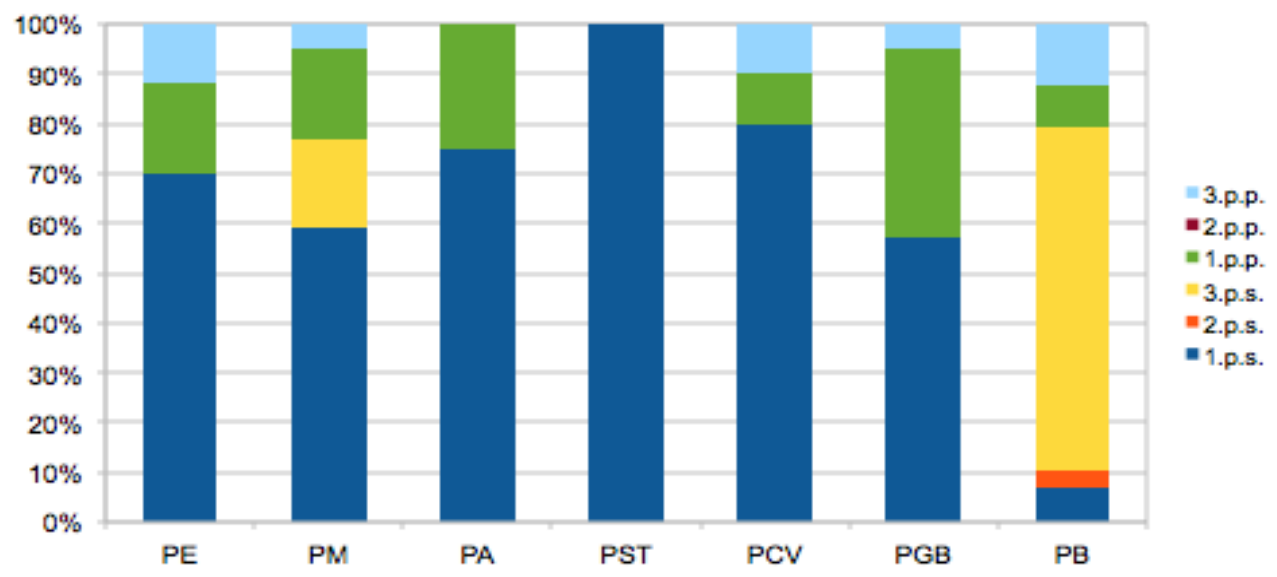

Observem-se alguns exemplos de DSs extraídos dos corpora deste estudo na primeira pessoa do singular:

(ISSN 2238-8060)

a. "eu... eu estive, estive aí na Mutamba, na rua." (PA)

b. "só que eu depois eu questiono-me se o nosso está em sétimo lugar..." (PE)

c. "eu, eu nunca tinha pensado nisso antes..." (PGB)

d. "...eu, eu disse aquilo mas nun[...] nunca cobra me atacou."

\footnotetext{
${ }^{16}$ Os gráficos apresentados nesta seção representam a frequência relativa do comportamento dos DSs em cada corpus, assim as percentagens em questão têm valor qualitativo e objetivam descrever graficamente o comportamento de determinados microparâmetros estruturais dos DSs. Devido à diferente natureza dos corpora a que tivemos acesso no momento, isto é, o fato de que não apresentam uma simetria no que se refere a aspectos extralinguísticos como sexo, escolaridade e faixa etária, não é objetivo deste estudo analisar a frequência de uso de cada variedade, tomando por base esses aspectos, mas trabalhar apenas com os tipos de comportamento morfossintático predominante em cada uma.
}

https://periodicos.unifap.br/index.php/letras

Macapá, v. 7, n. 2, 2을 semestre, 2017. 
Ao contrário do PB que possui, mesmo em pouca quantidade, DSs [-definidos], conforme já previsto em outros estudos (BRITTO, 2000; SILVA, 2004; COSTA, DUARTE; SILVA, 2004), nas demais variedades do português, todos os DSs são definidos, como se vê na Figura 2.

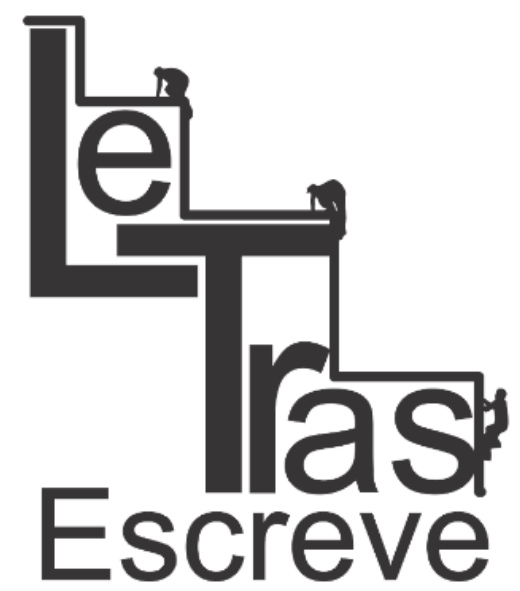

(ISSN 2238-8060)

Figura 2 - Frequência relativa de DS em variedades do português, tomando por base o traço de definitude.

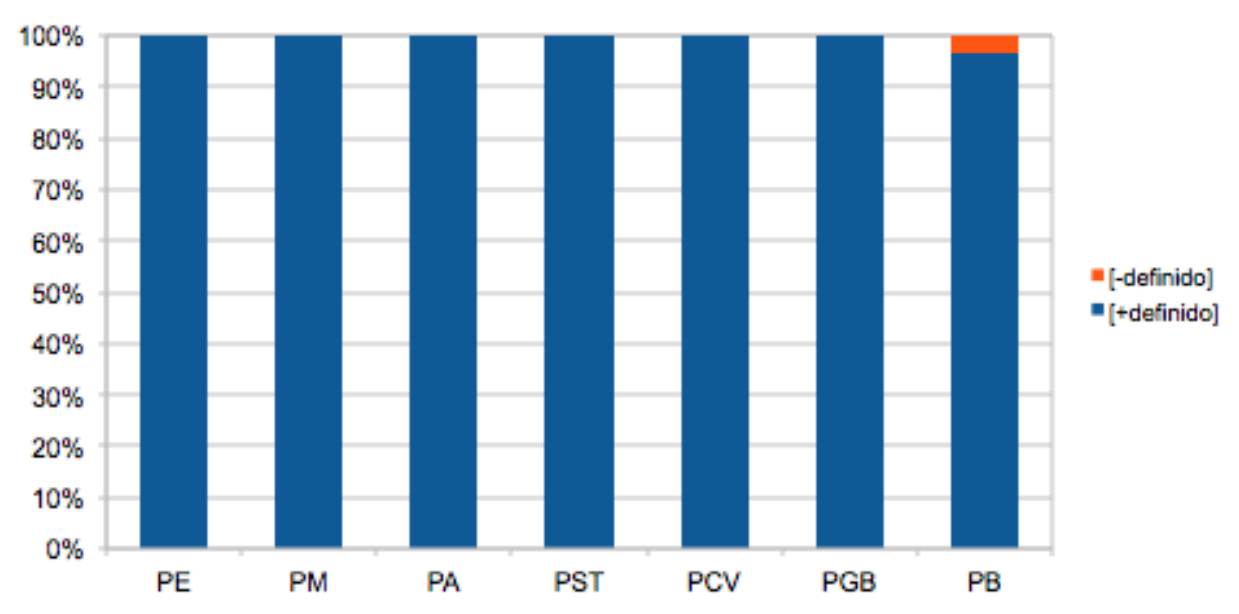

A seguir, observe-se um dos exemplos do corpus do PB com DS [-definido]:

$$
\begin{aligned}
& \text { "[...] quase umas - umas trinta a cinqüenta }{ }^{17} \text { pessoa que não é } \\
& \text { da comunidade - eles vem - tem uma casa em União e tudo } \\
& \text { [..]" (Comunidade de Muquém) }
\end{aligned}
$$

Em linhas gerais, a partir dos resultados obtidos, a hipótese inicial deste estudo se confirma: há maior proximidade das variedades africanas do português com o PE no que diz respeito aos padrões de

${ }^{17}$ Conservou-se a grafia usada no texto-fonte.

https://periodicos.unifap.br/index.php/letras

Macapá, v. 7, n. 2, 2o semestre, 2017. 
DSs: predominam pronomes de primeira pessoa. Na próxima seção, realizaremos a análise, tomando por base que a assimetria verificada entre o PB e as demais variedades estudadas decorre de diferentes subespecificações de traços de pessoa envolvidas no contexto de DSs, assumindo a proposta de composição de traços para o PB, de CarvaIho (2008), e os traços relevantes para a valoração de pessoa (CARVALHO; BRITO, 2014; CARVALHO, 2015).

3 Sobre o licenciamento dos DSs nas variedades do português: valoração, composicionalidade de traços e realização morfofonológica

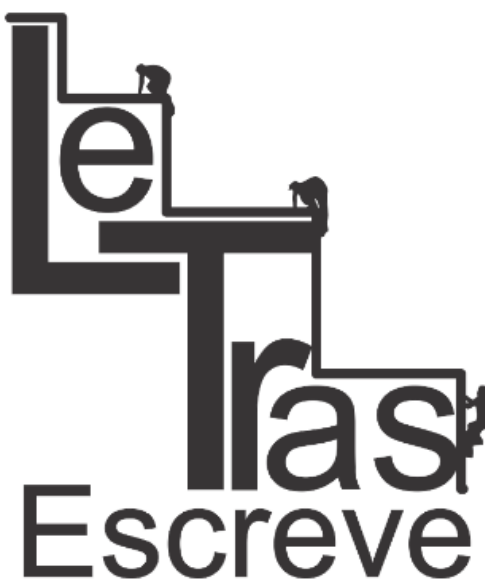

(ISSN 2238-8060)

A partir dos resultados apresentados, até o momento, o traço [+definido] do DP sujeito duplicado é bastante saliente, levando-nos a assumir que DSs são o resultado da realização de um traço de definitude. Como já apontam alguns trabalhos sobre o PB (CERQUEIRA, 2015a, 2015b; CARVALHO, 2008, 2016), a realização pronominal pessoal no português exige um efeito de definitude (efeito-D). Este efeito-D, como será visto adiante, é uma exigência de pronomes de primeira e segunda pessoa com referência específica.

Carvalho (2008) argumenta que, no que se refere aos pronomes, além dos traços de número, gênero e pessoa, outros traços podem estar a eles associados. Ao analisar o pronome você, por exemplo, e as possibilidades de essa forma ser interpretada como uma referência à segunda pessoa ou como uma referência arbitrária, é proposto pelo autor que esses outros traços (dentre os quais se incluem noções como definitude e especificidade) devem estar envolvidos na derivação, mas ressalta que "considerar que mais traços integram um pronome não quer dizer que todos esses traços devem estar necessa-

https://periodicos.unifap.br/index.php/letras

Macapá, v. 7, n. 2, 2o semestre, 2017. 
riamente legíveis ou mesmo presentes no curso da derivação" (CARVALHO, 2008, p. 57).

A associação entre a realização pronominal e os traços de definitude e de especificidade também é atestada por Cerqueira (2015b) para as formas pronominais de terceira pessoa no PB: o pronome "ele" acusativo é licenciado em contextos de leitura [+definida] e [+específica], em que ambos os traços são necessários para a gramaticalidade das sentenças; com o "ele" nominativo, apenas um dos traços precisa estar presente.

Como apontado em Carvalho (2016), anáforas realizadas co-

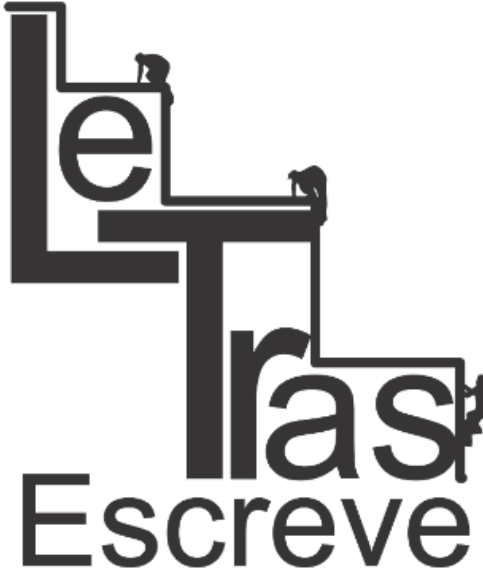

(ISSN 2238-8060) mo clíticos ou pronomes plenos precisam recuperar todo o conjunto de traços- $\phi$, incluindo, portanto, gênero (no caso da terceira pessoa, excluindo-se o se) e definitude. Em casos contrários, a retomada é feita apenas por pronomes nulos. Pronomes realizados exigem um conjunto completo de traços- $\phi$, que podem ser encontrados em determinantes definidos. Ainda, mesmo com anáforas não clíticas, gênero e número, juntamente com $D$ (um determinante), desempenham algum papel na sintaxe. Assim, referencialidade parece ser codificada através da valoração dos traços- $\phi$, incluindo gênero e definitude. Os exemplos de (6) a (8) mostram que apenas um DP definido pode ter uma anáfora realizada em $\mathrm{PB}^{18}$ :

(6) a. Eu consegui apartamento e já */ $\varnothing$ comprei/comprei *ele.

b. Eu consegui casa e já *a/ $\varnothing$ comprei/comprei *ela.

(7) a. Bicicletas são um ótimo meio de transporte porque elas/ $\varnothing$ não poluem.

\footnotetext{
${ }^{18}$ Os exemplos (6) a (8) foram submetidos a testes de gramaticalidade, os quais mostraram que a retomada só é permitida com o pronome nulo $(\varnothing)$. Entretanto, conforme julgamento de um dos pareceristas anônimos deste artigo, algumas variedades do PB parecem permitir a retomada do nome nu tanto pelo clítico acusativo quanto pelo pronome pleno em (6), mas não em (7) e (8). Asa razões dessa aceitabilidade extrapolam o escopo do presente trabalho.
}

https://periodicos.unifap.br/index.php/letras

Macapá, v. 7, n. 2, 2ㅇ semestre, 2017. 
b. Bicicleta é um ótimo meio de transporte porque *ela/ele/ $\varnothing$ não polui.
a. A criança $a_{i}$ diz que ela $a_{i / j} / \varnothing_{i}$ brinca de boneca.
b. Criança $a_{\mathrm{i}}$ diz que ${ }^{*}$ ela $_{\mathrm{i} / \mathrm{j}} / \varnothing_{\mathrm{i}}$ brinca de boneca.

Medeiros Jr.; Namiuti Temponi (2017) apontam que um efeito de definitude é o que licencia a presença de resumptivos em posição de objetos deslocados em PB, como ilustrado em (9). Os autores, ao analisarem estruturas de resumpção em interrogativas $D$-linked (discursivamente ligado), argumentam que sentenças como $(9 a, b)$ não recebem a mesma interpretação. Com base nas propostas de análise de Carvalho (2008) e de Cerqueira (2015a, 2015b), Medeiros

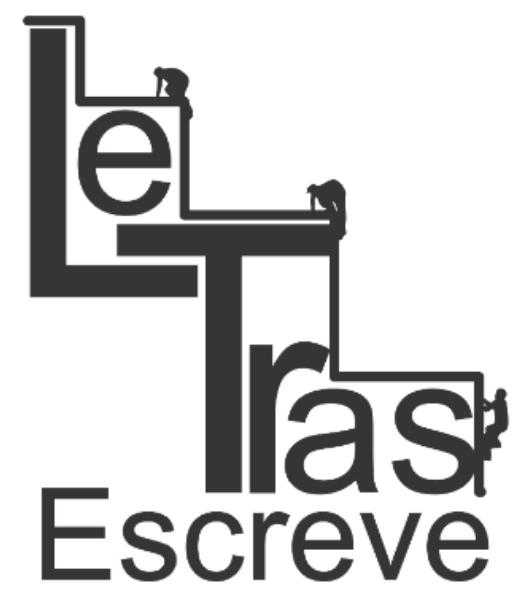

(ISSN 2238-8060) Jr. e Namiuti Temponi (2017) defendem que o resumptivo em (9b) expressa um traço de especificidade, o qual não pode ser satisfeito pelo elemento-Q $D$-linked. O constituinte $D$-linked é copiado da posição em que o resumptivo é pronunciado:
a. [Que livro] $]_{i}$ que você precisa [___ $]_{i}$ ?
b. [Que livro $]_{i}$ que você precisa $d[e l e]_{i}$ ?

Essas evidências parecem sugerir que os traços definitude/especificidade desempenham um papel na sintaxe do português. Essa assunção, na verdade, é atestada em um grande número de línguas naturais, que apresentam morfossintaxe para expressar uma relação de concordância de definitude (cf. ANDROUTSOPOULOU, 1995, para o grego moderno; GIUSTI, 1997, para o hebraico e o albanês; NISHIYAMA, 1998, para o buginês, e CORBETT; BOND, 2016, para o norueguês e o archi).

Com base nos argumentos apresentados neste trabalho e nos

https://periodicos.unifap.br/index.php/letras

Macapá, v. 7, n. 2, 20 semestre, 2017. 


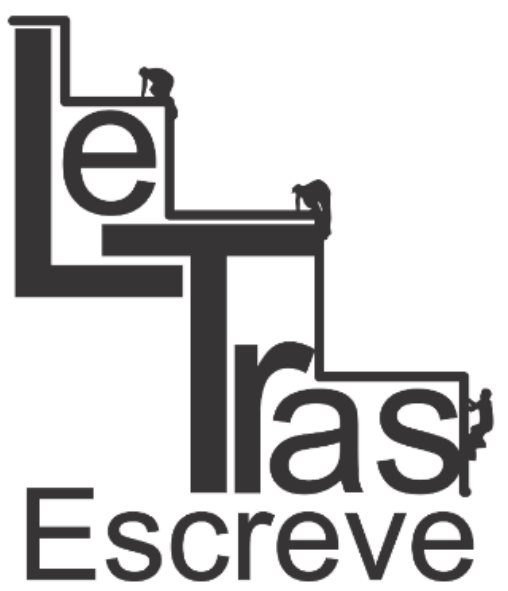

(ISSN 2238-8060)

supracitados, propomos que definitude é um requisito no licenciamento de pronomes com papel resumptivo no PB. Essa análise pode se estender a outros contextos nas variedades do português. Consideraremos, assim, que DSs são estruturas tópicas que possuem um resumptivo na posição do sujeito movido.

Carvalho (2015) discute o comportamento da 1 a pessoa do singular no português a partir do comportamento da primeira pessoa do singular não marcada no PB encontrado em dados do português afro-brasileiro coletados na comunidade de Helvécia, Bahia e Muquém, Alagoas. Baseado na subespecificação de traços proposta em trabalhos anteriores (CARVALHO, 2008, 2010, 2015; CARVALHO; BRITO, 2014), o autor descreve um possível caminho para explicar o licenciamento de pessoa a partir da valoração de uma geometria de traços, inspirada em Harley e Ritter (2002) e ilustrada em (10). [Ф] representa qualquer expressão referencial (incluindo pronomes) e a valoração de seus traços nas relações de concordância morfossintática, que se dá a partir de uma leitura da relação superconjunto/subconjunto da hierarquia de traços em (10), determina a forma e a função dos (pro)nominais. Segundo Carvalho (2015, p. 149), “[ф] é o nó raiz da estrutura de concordância- $\phi$. Sua total subespecificação gera estruturas maximamente subespecificadas, i.e., que podem ocorrer em qualquer posição sintática, seja ela $A$ ou $\bar{A}^{\prime \prime}$. Os traços relevantes para pessoa são aqueles dominados por $[\pi]$. Esse nó domina os traços relevantes para as possíveis leituras de pessoa em uma língua natural ${ }^{19}$ :

\footnotetext{
${ }^{19}$ Mantivemos a notação na língua original (inglês). As abreviações em (10) representam participant ([prtc]), speaker ([spkr]), addressee ([addr]), definite ([def]), specific ([spcf]), feminine ([fem]), animate ([anim]), human ([hum]). Para uma definição de cada traço da notação apresentada em (10), ver Carvalho (2008, 2017).
}

https://periodicos.unifap.br/index.php/letras

Macapá, v. 7, n. 2, 2o semestre, 2017. 


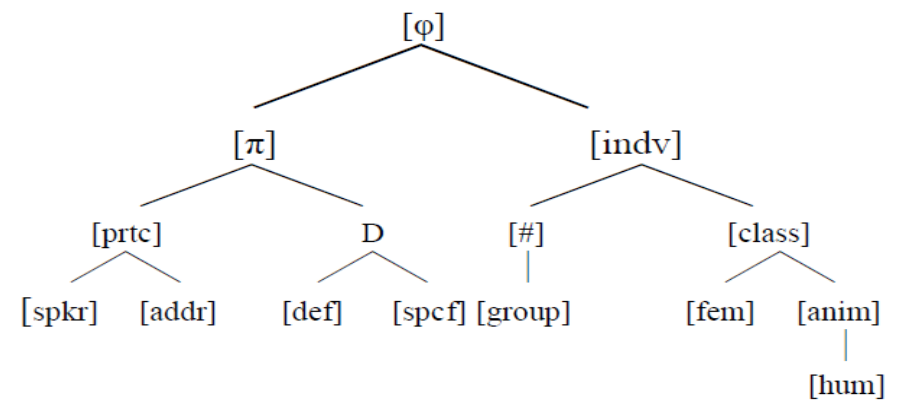

Como pode ser capturado da geometria em (10), definitude/especificidade são traços dominados por $\mathrm{D}$ e $\pi$, respectivamente. Carvalho (2015), baseado na notação acima, propõe a seguinte configuração para as estruturas pronominais pessoais no PB:

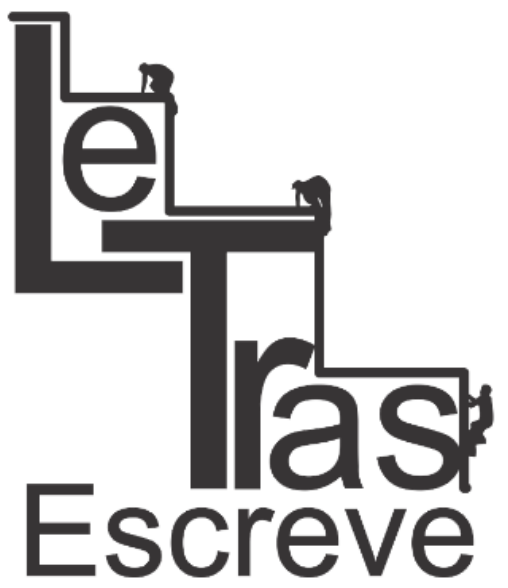

(ISSN 2238-8060)

(11) $1^{\underline{a}}$ pessoa:

a. Definido: $[\phi[\pi[$ part $[$ spkr $]][D[$ spcf $][$ def $]]]]$

b. Arbitrário: $[\phi[\pi[$ part[spkr]][D]]]

$2^{\underline{a}}$ pessoa:

a. Definido: $[\phi[\pi[$ part[addr $]][D[s p c f][d e f]]]]$

b. Arbitrário: $[\phi[\pi[$ part[addr $][D]]]$

$3^{\underline{a}}$ pessoa: $[\phi[\pi[D[\ldots]]]]^{20}$

Primeira e segunda pessoa são, necessariamente, definidas e específicas em contextos de referência definida e estabelecem uma relação de complementação com os traços dominados por $\mathrm{D}$, como visto em $(10)^{21}$. A terceira pessoa pode ou não apresentar a camada $D$

${ }^{20}$ Cerqueira (2015a) demonstra que o pronome de terceira pessoa na posição de objeto no PB exige, em sua composição, pelo menos um dos traços imediatamente dominados por D.

${ }^{21}$ Como apontado por um parecerista anônimo, os traços dominados por D não estabelecem uma relação de dominância imadiata com [prtc], mas apresentam algum tipo de vínculo, estreito, que pode ser estabelecido em termos de uma dependência estrutural mais complexa, como precedência, o que não enfraquece as relações que podem ser estabelecidas entre os nós propostos em (10). Além do mais, discursivamente, falante ([sp-

https://periodicos.unifap.br/index.php/letras

Macapá, v. 7, n. 2, 2o semestre, 2017.

108 


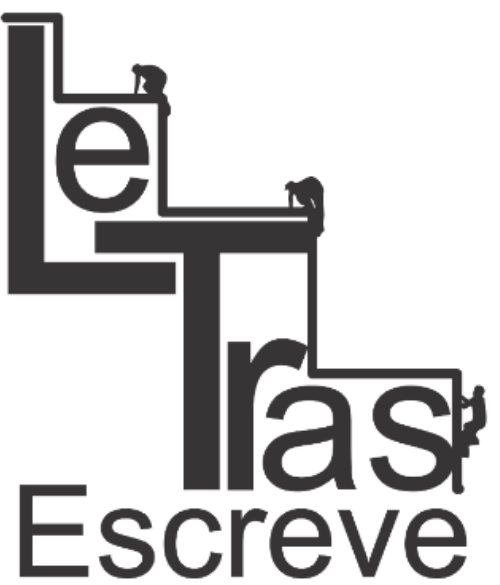

(ISSN 2238-8060) em sua estrutura, visto que podem apresentar função expletiva em algumas línguas (cf. o it em inglês e o il em francês). Em português, por seu turno, a terceira pessoa não possui uma contraparte não definida/específica, devendo apresentar, pelo menos, um dos traços dominados por $D$ na geometria. Isso explica a impossibilidade de leitura arbitrária da terceira pessoa nessa língua (CERQUEIRA, 2015b).

Se Starke $(2009 ; 2014)$ estiver correto quando afirma que a sintaxe opera com traços e não com itens lexicais já formados e que sua realização morfofonológica depende exclusivamente de operações pós-sintáticas, podemos defender que o pronome duplicado nas DSs são a realização de pelo menos um dos traços dependentes de D. Assumimos que o pronome ele em (3b), repetido abaixo, é a realização morfofonológica dos traços dominados por [D], neste caso, definitude e especificidade, de um constituinte (o DP meu irmão), que foi movido para uma posição de tópico ${ }^{22}$ :

\section{“[...] meu irmão... ele num é home pa juntá um casal... [...] (PB)}

Já nas outras variedades do português aqui estudadas, a predominância é da primeira pessoa, que, como já mencionado acima, é sempre definida em contextos de DSs, ou seja, possui sempre os traços de definitude/especificidade em sua composição, o que engatilha o efeito-D supramencionado. Isso explica a necessidade de duplicação dos pronomes de primeira pessoa em contextos de DS nessas variedades, visto que a exigência prevista por Cerqueira (2015a, 2015b) parece ser dos traços dominados por D e, não especificamen-

kr]) e ouvinte ([addr)] são necessariamente conhecidos no universo discursivo por constituírem eles próprios esse universo, o que por sí só já determina sua natureza definida e específica.

${ }^{22}$ Por questões de espaço, não desenvolveremos a análise do movimento do DP sujeito à posição de tópico. Para uma discussão sobre o tema nas variedades do português aqui discutidas, ver Santos (2010), Campos e Santos (2012), Britto (2000) e Silva (2004, 2013).

https://periodicos.unifap.br/index.php/letras

Macapá, v. 7, n. 2, 2o semestre, 2017. 
te, de uma pessoa do discurso (terceira). Assim, a mesma análise proposta para DSs em PB se aplica às demais variedades do português, pois as exigências estruturais de definitude parecem independer da pessoa do discurso e devem ser satisfeitas sempre que o argumento externo (definido) for movido para uma posição-Ā. Dessa maneira, como apontado por Medeiros Jr.; Namiuti Temponi (2017, p. 93-94),

[i]sso permite que o sistema computacional, ao copiar um constituinte para outra posição na estrutura da sentença, opere com traços em ambas as cópias e, desse modo, torna-se possível que um traço ou conjunto de traços seja realizado por um item lexical distinto, em cada uma das cópias.

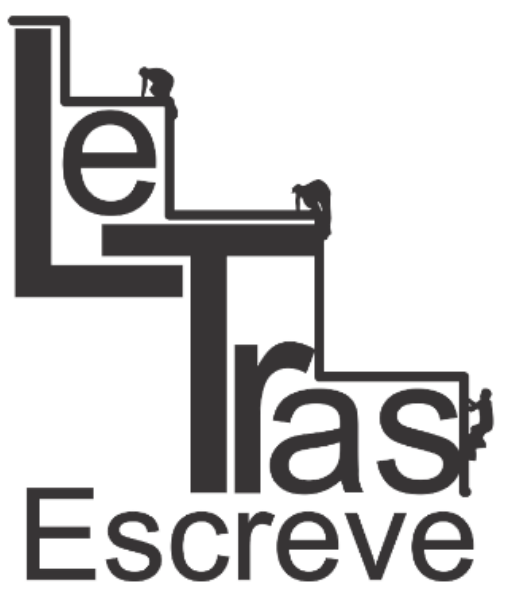

(ISSN 2238-8060)

\section{Considerações finais}

A partir da análise de dados de fala espontânea de sete variedades do português faladas no mundo, o artigo explorou a possibilidade de reinterpretação descritiva da estrutura interna dos elementos que regem a concordância no português. Essa proposta tem a vantagem de ser mais abrangente, incluir fenômenos, como os DSs, e descrever de forma mais completa os mecanismos de articulação da concordância no português, sem restrição à morfossintaxe do verbo. 
Nas estruturas de DSs aqui estudadas, a posição argumental na qual o DP sujeito é originalmente gerado possui requerimento que envolve os traços dominados por [D], e sua interpretabilidade é lida como a realização por um pronome (resumptivo) na interface articulatório-perceptual.

Em suma, aventamos a hipótese de que diferentes gramáticas geram diferentes spell-outs a partir de estruturas de traços distintas. Nosso argumento parte do princípio de que a gramática estabelecida no contexto das variedades em análise oferece um único padrão de concordância, cuja variação se dá em termos de subespecificação dos traços.

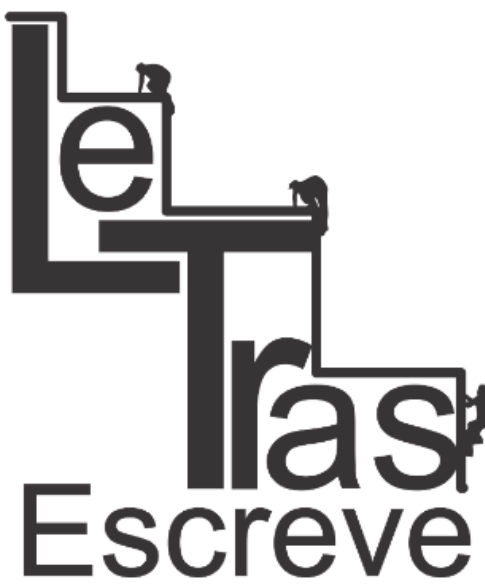

(ISSN 2238-8060)

\section{Referências}

ANDROUTSOPOULOU, A. The licensing of adjectival modification. In: CAMACHO, J. et. al. (eds.). WCCFL 14: The Proceedings of the Fourteenth West Coast Conference on Formal Linguistics. Chicago: CSLI Publications, 1995. p. 17-32.

ARAÚJO, E. As construções de tópico. In: LUCCHESI, D.; BAXTER, A.; RIBEIRO, I. (orgs.). O Português Afro-Brasileiro. Salvador: EDUFBA, 2009, p. 231-250.

BACELAR DO NASCIMENTO, M. F. et al. Corpus África: as cinco variedades africanas do português. FROTA, S.; SANTOS, A. L. (orgs.) Textos Seleccionados: XXIII Encontro Nacional da Associação Portuguesa de Linguística. Lisboa: APL, 2008, p. 373-384.

BARBOSA, P. A new look at the null subject parameter. In: COSTA, J.; GOEDEMANS, R.; VAN DE VIJVER, R. (eds.). Proceedings of ConSOLE IV. Leiden: Leiden University, 1996, p. 375-395.

BARBOSA, P. Two kinds of subject pro. Studia Linguistica, v. 63, n. 1, 
p. 2-58, abr. 2009.

BRITTO, H. Syntactic codification of categorical and thetic juggments in Brazilian Portuguese. In: KATO, M. A.; NEGRÃO, E. V. (eds.). Brazilian Portuguese and the null subject parameter. Madrid: Iberoamericana, 2000, p. $195-222$

CAMPOS, E. A.; SANTOS, E. F. A categoria tópico: aproximações entre o Português do Brasil e o Português de Angola. Papia, v. 22, n. 1, p. 129-140, 2012.

CARVALHO, D. S. A estrutura interna dos pronomes pessoais em português brasileiro. Tese (Doutorado em Linguística). Universidade Federal de Alagoas, Maceió, 2008.

. Geometria de traços e a sintaxe de pronomes no português

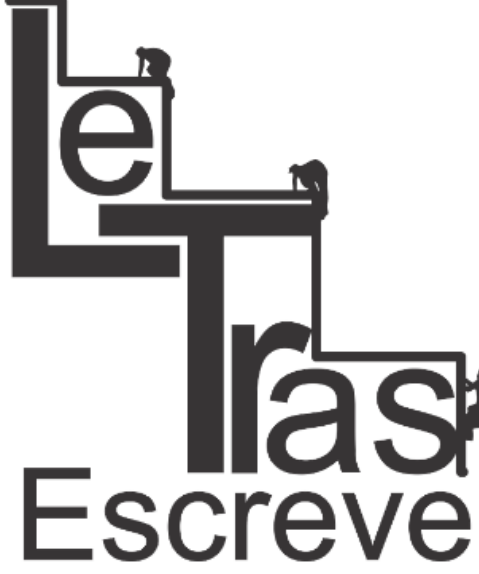

(ISSN 2238-8060) brasileiro. In: BRITO, A. M., et al. (orgs.). Textos Seleccionados: XXV Encontro Nacional da Associação Portuguesa de Linguística. Lisboa: APL, 2010, p. 245-261.

. Sobre pessoa e referencialidade no português. Revista Letras, Curitiba, n. 91, n.1, p. 131-157, jan./jun. 2015.

. Concordância fracassada é, na verdade, relativização de traços. In: PILATI, E. N. S. (org.). Temas em teoria gerativa: homenagem a Lucia Lobato. Curitiba, PR: Blanche, 2016, p. 103-129.

Uma proposta de estrutura interna para os pronomes pessoais no português brasileiro. Signótica, Goiânia, v. 29, n. 2, p. 455-481, jul./dez. 2017.

; BRITO, D. Pronomes nulos e referência no português afrobrasileiro. Veredas, v. 18, n. 1, p. 23-43, jan./jun. 2014.

CERQUEIRA, F. O. A sintaxe do pronome acusativo de terceira pessoa no português brasileiro. Dissertação (Mestrado em Língua e Cultura). Universidade Federal da Bahia, Salvador, 2015a.

CERQUEIRA, F. O. Reflexos semânticos na sintaxe de terceira pessoa.

https://periodicos.unifap.br/index.php/letras

Macapá, v. 7, n. 2, 2ㅇ semestre, 2017. 
Letrônica: Revista Digital do Programa de Pós-Graduação em Letras da PUCRS, Porto Alegre, v. 8, n. 2, p. 422-437, jul./dez. 2015b.

CORBETT, G. G. Agreement in Slavic (Version 1, 12 January 1998). Ms. Universidade de Indiana, 1998. Disponível em: <http://www.indiana. edu/slavconf/linguistics/corb.pdf>. Acesso: 10 jun. 2017.

; BOND, O. Why are there exactly five types of morphosyntactic features. Ms. Universidade de Nápoles, Federico II, 2016.

Disponível

em:

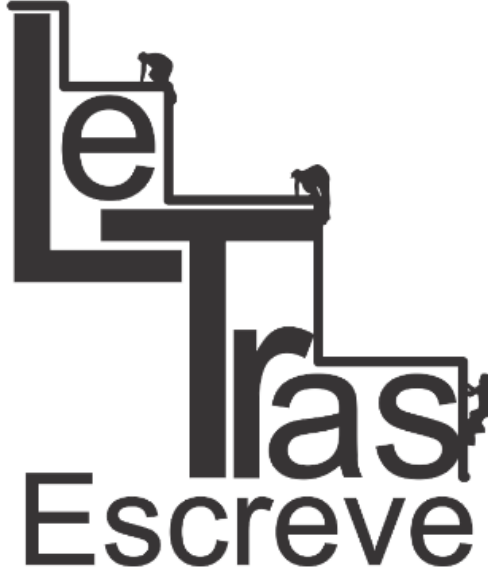

(ISSN 2238-8060)
<https://typecraft.org/w/images/1/19/Corbett\%26BondSLE2016-

slides-final.pdf>. Acesso: 2 mar. 2017. [Comunicação no 49. ${ }^{\circ}$ Encontro Anual da SLE]

COSTA, J.; DUARTE, I.; SILVA, C. Construções de redobro em português brasileiro: sujeitos tópicos vs. soletração do traço de pessoa. Leitura, Maceió, v. 33, n. 1, p. 135-145, jan./dez. 2004.

COUTO, H.; EMBALÓ, F. Literatura, língua e cultura na Guiné-Bissau um país da CPLP. PAPIA: Revista Brasileira de Estudos do Contato Linguístico, v. 20, n. 1, p. 11-253, jan./dez. 2010.

DUARTE, M. E. L. A perda do princípio 'Evite Pronome' no português brasileiro. Tese (Doutorado em Linguística). Universidade Estadual de Campinas, Campinas, 1995. . The loss of the 'avoid pronoum' principle in Brazilian Portuguese. In: KATO, M. A.; NEGRÃO, E. V. (eds.). Brazilian Portuguese and the null subject parameter. Madrid: Iberoamericana, 2000, p. 17-36.

GONÇALVES, P. Aspectos morfossintáticos da gramática do português de Moçambique: a concordância nominal e verbal. In: VIEIRA, S. R.; BRANDÃO, S. F. (orgs.) Cuadernos de la Alfal 7, 2015, p. 9-16.

GONÇALVES, R. Mudança linguística e variação no português de São Tomé. In: COLÓQUIO INTERNACIONAL "SÃO TOMÉ E PRÍNCIPE NUMA

https://periodicos.unifap.br/index.php/letras

Macapá, v. 7, n. 2, 2o semestre, 2017. 
PERSPECTIVA INTERDISCIPLINAR, DIACRÓNICA E SINCRÓNICA", Lisbo-

a, 2012. Actas... Lisboa: AULP, 2012, p. 413-430.

GIUSTI, G. The categorial status of determiners. In: HAEGEMAN, L.

(ed.). The new comparative syntax. London: Longman, 1997, p. 95-

123.

HAGEMEIJER, T. As línguas de S. Tomé e Príncipe. Revista de Crioulos de Base Lexical Portuguesa e Espanhola, v. 1, n. 1, p. 1-27, jan./dez. 2009.

HARLEY, H.; RITTER, E. Person and number in pronouns: a featuregeometric analysis. Language, v. 78, n. 3, p. 482-526, set. 2002.

HOLMBERG, A.; NAYUDU, A.; SHEEHAN, M. Three partial null subject

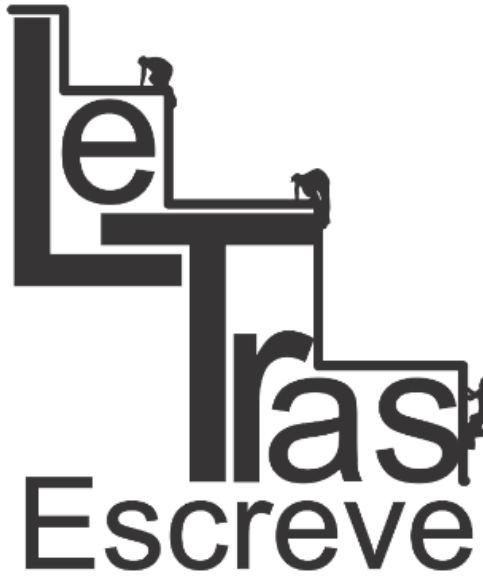

(ISSN 2238-8060) languages: a comparison of Brazilian Portuguese, Finnish and Marathi. Studia Linguistica, v. 63, n. 1, p. 59-97, abr. 2009.

LORENZINO, G. Afro-Portuguese creole $a$ : Its Kwa origins and discourse pragmatics. African Journal of Languages and Linguistics, Washington, DC, v. 1, n. 1, p. 45-67, 1996.

MATTOS E SILVA, R. V. Diversidade e unidade: a aventura linguística do português. Ms. Universidade Federal da Bahia, 1998. Disponível em: <http://cvc.instituto-camoes.pt/hlp/biblioteca/diversidade.pdf>. Aceso: 10 mar. 2017.

MEDEIROS JR., S. A.; NAMIUTI-TEMPONI, C. Resumpção e realização de traços-phi. In: CARVALHO, D. S.; BRITO, D. Pronomes: morfossintaxe e semântica. Salvador: EDUFBA, 2017, p. 81-96.

MOTA, M. A. Para uma tipologia da concordância sujeito-verbo, em português falado: contributos do português de Luanda e de Cabo Verde. In: VIEIRA, S. R.; BRANDÃO, S. F. (orgs.) Cuadernos de la Alfal 7, 2015, p. 17-35.

MOURA, D. Resquícios de Palmares: o que uma comunidade quilombola nos diz. Maceió: EDUFAL, 2009. 
NISHIYAMA, K. Free Order in Buginese Noun Phrases and DP-Internal XP-Movement. In" TAMANJI, N.; KUSUMOTO, K. (eds.) Proceedings of NELS 28. Amherst, MA: GLSA, 1998, p. 121-135.

OLIVEIRA, M. S.; BAIO, J. P.; INJAI, B. F. A inserção do "contínuo português guineense" às variedades africanas do português. Todas as Letras: Revista de Língua e Literatura, São Paulo, v. 15, n. 1, p. 130-137, 2013.

PETTER, M. M. T. Aspectos morfossintáticos comuns ao português angolano, brasileiro e moçambicano. PAPIA: Revista Brasileira de Estudos do Contato Linguístico, v. 19, n. 1, p. 201-220, jan./dez. 2009.

PONTES, E. Sujeito: da sintaxe ao discurso. São Paulo/Brasíla: Ática/INL, 1986.

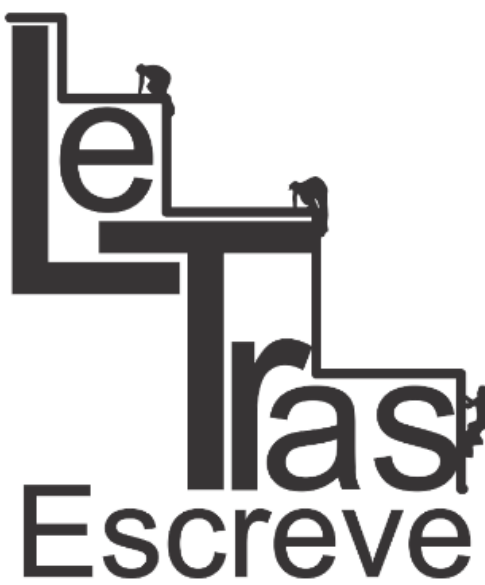

(ISSN 2238-8060)

SALLES, A. A. F. O fenômeno "sujeito duplo" em PB. Dissertação (Mestrado em Estudos da Linguagem). Universidade Estadual de Londrina, Londrina, 2004.

SANTOS, E. F. A periferia esquerda da sentença no português de Angola. Dissertação (Mestrado em Letras). Universidade de São Paulo, São Paulo, 2010.

SILVA, C. R. T. A natureza de AGR e suas implicações na ordem VS: um estudo comparativo entre o português brasileiro e o português europeu. Tese (Doutorado em Linguística). Universidade Federal de Alagoas, Maceió, 2004.

. Comportamento e natureza dos sujeitos duplicados no crioulo caboverdiano e no português falado em comunidades quilombolas. In: MOURA, M. D. D.; SIBALDO, M. A. (Org.). Para a História do Português Brasileiro: Sintaxe Comparativa entre o português brasileiro e línguas crioulas de base lexical portuguesa. Maceió: EDUFAL, 2013, p. 167-206.

; ZIOBER, F. M. Sujeito duplos no português brasileiro, cabo-

https://periodicos.unifap.br/index.php/letras

Macapá, v. 7, n. 2, 2o semestre, 2017. 
verdiano e satome. In: ENCONTRO DA SOCIEDADE BRASILEIRA DE ESTUDOS CRIOULOS E SIMILARES, VIII, São Paulo, 2012. Caderno de resumos... São Paulo: Humanitas, 2014, p. 110-117.

SOUZA, M. et. al. (org.). A fala de remanescentes quilombolas de Portalegre do Brasil. Mossoró: Edições UERN, 2011. [recurso eletrônico; 1 CD-ROM].

STARKE, M. Nanosyntax: a short primer to a new approach to language. Nordlyd: Troms $\varnothing$ University Working Papers on Language \& Linguistics, Tromsø, v. 36, n. 1, p. 1-6, 2009. . Towards an elegant solution for language variation: variation reduces to the size of lexically stored trees. In: PICALLO, C. (ed.) Linguistic Variation in the Minimalist Framework. Oxford: Oxford University Press, 2014, p. 140-154.

Artigo recebido em 10/08/2017

Aceito em 27/03/2018

(ISSN 2238-8060) 